\title{
Prevalence of diabetes mellitus among tuberculosis patients in Sub-Saharan Africa: a systematic review and meta-analysis of observational studies
}

Animut Alebel ${ }^{1 *}$ (D, Amsalu Taye Wondemagegn ${ }^{1}$, Cheru Tesema$^{1}$, Getiye Dejenu Kibret ${ }^{1}$, Fasil Wagnew ${ }^{1}$, Pammla Petrucka ${ }^{2,3}$, Amit Arora ${ }^{4,5,6,7}$, Amare Demsie Ayele ${ }^{8}$, Mulunesh Alemayehu ${ }^{1}$ and Setegn Eshetie ${ }^{8}$

\begin{abstract}
Background: Tuberculosis and diabetes mellitus are significant global public health challenges. In Sub-Saharan Africa, study findings regarding prevalence of diabetes mellitus amongst tuberculosis patients have been inconsistent and highly variable. Therefore, this systematic review and meta-analysis estimates the overall prevalence of diabetes mellitus among tuberculosis patients in Sub-Saharan Africa.

Methods: Four international databases (PubMed, Google Scholar, Science Direct and Cochrane Library) were systematically searched. We included all observational studies reporting the prevalence of DM among TB patients in Sub-Saharan Africa. All necessary data for this review were extracted using a standardized data extraction format by two authors (CT and AA1). STATA Version 14 statistical software was employed to conduct meta-analysis. The Cochrane Q test statistics and $P$ test were used to assess the heterogeneity of the studies. Finally, a random effects meta-analysis model was computed to estimate the pooled prevalence of diabetes mellitus in TB patients. Besides, subgroup analysis was done based on different factors.

Results: In the meta-analysis, sixteen studies fulfilled the inclusion criteria and were included. The findings of these 16 studies revealed that the pooled prevalence of diabetes mellitus among tuberculosis patients in Sub-Saharan Africa was $9.0 \%$ (95\% Cl: 6.0, 12.0\%). The highest prevalence of diabetes mellitus among tuberculosis patients was found in Nigeria (15\%), followed by Tanzania (11\%), and then Ethiopia (10\%). Besides, the prevalence of diabetes mellitus among HIV infected TB patients was (8.9\%) which is slightly higher than HIV uninfected (7.7\%) TB patients.

Conclusion: Diabetes mellitus among tuberculosis patients in Sub-Saharan Africa was significantly high. Moreover, this study found that there was a high prevalence of DM among HIV infected than uninfected TB patients. It is strongly recommended to screen for DM among TB patients and special emphasis should be given for early screening of DM among TB/HIV co-infected patients.
\end{abstract}

Keywords: Type1/type 2 diabetes mellitus, Tuberculosis, Sub-Saharan Africa

\footnotetext{
* Correspondence: animut.a23@gmail.com

${ }^{1}$ College of Health Sciences, Debre Markos University, P.O. Box 269, Debre

Markos, Ethiopia

Full list of author information is available at the end of the article
}

(c) The Author(s). 2019 Open Access This article is distributed under the terms of the Creative Commons Attribution 4.0 International License (http://creativecommons.org/licenses/by/4.0/), which permits unrestricted use, distribution, and reproduction in any medium, provided you give appropriate credit to the original author(s) and the source, provide a link to the Creative Commons license, and indicate if changes were made. The Creative Commons Public Domain Dedication waiver (http://creativecommons.org/publicdomain/zero/1.0/) applies to the data made available in this article, unless otherwise stated. 


\section{Background}

Currently, non-communicable diseases (NCDs) are a growing worldwide epidemic that disproportionately affects low- and middle-income countries (LMIC) where, concomitantly, the burden of infectious diseases is high. The prevalence of NCDs in low-income countries in 1990 was reported to be $47 \%$, but it is projected to rise to $69 \%$ by 2020 and NCDs will likely exceed cases of communicable diseases by 2030 [1]. Advancing industrialization and urbanization have contributed to lifestyle changes, primarily in dietary habits, leading to increased rates of obesity and Type II diabetes mellitus (DM). Globally, there are approximately 422 million adults living with DM of which about $80 \%$ of cases reside in LMIC [2-4], where concomitantly communicable diseases, such as tuberculosis (TB), are often endemic [5]. Type 2 DM accounts for about $90 \%$ of the diabetes with even higher prevalence in urban and aged populations [6].

The dual burden of communicable and non-communicable epidemics facing Sub-Saharan Africa (SSA) further complicates the experiences and implications of these diseases. There are known negative impacts in co-morbid cases [7]. Some studies showed that DM and TB are the two interlaced diseases $[8,9]$. This strong correlation is especially, accentuated in LMIC, where almost 95\% of the world's population with TB and 70\% with DM live [10]. Different studies conducted elsewhere disclosed that presence of DM increases the life time risk of developing TB by three-folds $[8,11,12]$. The physiologic association between the two diseases is not fully explored, but studies suggested that DM weakened the immune response, which, in turn, enhances the infection of Mycobacterium tuberculosis and/or progression from latent to active disease state [13]. Alternately, TB can temporarily cause impaired glucose tolerance and might predispose patients to DM [14]. Moreover, chronic infections such as TB are associated with idiopathic hyperglycemia, which occurs due to increased production of counter-regulatory stress hormones such as epinephrine, glucagon, cortisol, and growth hormone which act synergistically [15].

In SSA, study findings regarding the prevalence of DM among TB patients differ by geographical region and the background characteristics of the study participants $[9,16-30]$. These studies reported that the prevalence of DM among TB patients in SSA ranged from $1.9 \%$ in Benin [30] to 38\% in Nigeria [22]; however, in SSA there was no regional-based study, which considers the prevalence of DM among TB patients. Therefore, the aim of this systematic review and meta-analysis was to estimate the pooled prevalence of DM among TB patients in SSA. The findings of this systematic review and meta-analysis will highlight the prevalence of DM among TB patients in SSA with implications to improve health care workers' interventions, to ensure their cost-effectiveness, and accelerate the reduction of the DM prevalence among TB patients.

\section{Methods}

This systematic review and meta-analysis was intended to estimate the pooled prevalence of DM among TB patients in SSA. The protocol for this review was registered in the International Prospective Register of Systematic Reviews (PROSPERO), University of York Centre for Reviews and Dissemination (Registration Number CRD42017073403) on the 31th of August, 2017. To ensure scientific rigor, the Preferred Reporting Items for Systematic Reviews and Meta-Analysis (PRISMA) guidelines was used [31]. Four international databases-PubMed, Google Scholar, Science Direct and The Cochrane Library, were systematically searched. To search relevant articles for this study, we used the following keywords "prevalence", "diabetes mellitus", "type one diabetes mellitus", "type two diabetes mellitus", "tuberculosis", and "Sub-Saharan Africa". The key terms were used separately and/ or in combination using Boolean operators like "OR" or "AND". The literature search from the above databases was done from August 10 to September 9, 2017. All papers published until the 9th of September, 2017 were included in this review.

\section{Eligibility criteria \\ Inclusion criteria}

Study area All studies conducted in SSA countries

Publication condition Manuscripts published in peer reviewed journals

Study design For this review, we included all observational study designs (cross-sectional, case-control, and cohort studies) reporting the prevalence of DM among TB patients in SSA.

Language Articles reported in the English language were included.

\section{Exclusion criteria}

We excluded papers that were not fully accessible, after at least two email contact attempts with the primary authors. Exclusion of these articles was due to inability to assess the quality of articles in the absence of full text.

\section{Outcome of interest}

Primarily, this study aims to estimate the pooled prevalence of DM among TB patients in SSA. The prevalence was calculated by dividing the number of individuals who have DM to the total number of patients who have TB (sample size) multiplied by 100 . Secondly, this study aims to compare the prevalence of DM among HIV infected and uninfected TB patients. 


\section{Operational definitions}

Based on the World Health Organization (WHO) DM diagnostic criteria, the patent is considered as diabetic if he or she fulfilled the following two conditions: when the random blood glucose (RBG) value is $\geq 200 \mathrm{mg} / \mathrm{dl}$ and/or fasting blood glucose (FBG) value $\geq 126 \mathrm{mg} / \mathrm{dl}$ on two separate occasions [32] plus the patient shows the classical signs and symptoms of DM.

Positive TB status (PTB) was diagnosed when a patient fulfilled at least two of the following criteria: positive sputum smear by microscopic examination of Ziehl-Neelsen-stained sputum slides for acid-fast bacilli, chest radiographs with suggestive features of $\mathrm{TB}$, and/or clinical symptoms and signs of TB [33].

\section{Data extraction}

Two authors (CT and AA1) independently extracted all necessary data using a standardized data extraction format. The data extraction format included primary author, publication year, country of the study, study design, sample size, and prevalence.

\section{Quality assessment}

First of all, the Newcastle-Ottawa Scale (NOS) quality assessment tool for cross-sectional studies was adapted [34]. Then after, the two authors (AA1 and CT) independently assessed the quality of included peer reviewed articles using the above tool. If there were differences in the scoring of articles between the two reviewers, the differences were addressed by taking the mean score of the two authors or by involving the third author. After reviewing different literatures, we declared that articles scored $\geq 6$ points out of 10 were considered to be high-quality (see Additional file 1). The NOS tool emphasized on three main issues. The principal component of the tool graded from five stares and mainly emphasized on the methodological quality of each primary study. The other component of the tool graded from two stars and mainly concerns about the comparability of each study. The last component of the tool graded from three stars and used to assess the outcomes and statistical analysis of each original study.

\section{Statistical analysis, sub-group analysis, and publication bias}

We used a Microsoft Excel spreadsheet for data extraction and STATA Version 14 statistical software for data analysis. The descriptive data were presented using a table to describe the characteristics of each primary study. Besides, the point prevalence of each study as well as the overall prevalence were described using a forest plot graph. The forest plot was interpreted as follows: the horizontal line shows the 95\% CI and the black box represents the Wight of each study. Moreover, an explanatory data analysis using Q-statistics and $I^{2}$ test was conducted to assesses the random variations between each primary study [35]. In this study, heterogeneity was interpreted as an $\mathrm{I}^{2}$ value $=0 \%$ no heterogeneity, $25 \%=$ low, $50 \%=$ moder ate, and $75 \%=$ high [36]. Based on the above testes, the primary studies included in this meta-analysis exhibited a significant random variation $\left(I^{2}=97.5 \%\right.$ with Cochrane Q-statistics $p$-value $<0.001$ ), which forced us to use a random effects meta-analysis model to compute the Der Simonian and Laird's pooled effect. Additionally, we computed a subgroup analysis based on different variables including country of the primary studies, HIV infection status, and sample size. Besides, an advanced statically analysis like a univariate meta-regression model was done based on sample size and year of publication as covariates to identify the sources of random variations among included primary studies. Lastly, publication bias was assessed using Egger's and Begg's tests at 5\% level of significant [37].

\section{Results}

In the first step of our search, 1467 articles were retrieved on the prevalence of DM among TB patients. Of these, 450 articles were excluded due to duplication. From the remaining 1017 articles, 720 articles were excluded after reviewing of their titles and abstracts based on an assessment as they were non-relevant to the aim of this review. The remaining 297 abstracts were screened, yielding an additional 234 being excluded as non-relevant to this study. A total of 63 full text articles were accessed and assessed for eligibility based on the pre-set inclusion criteria. This step resulted in further exclusion of 47 articles primarily due to the study locations. Among these, five of the studies were conducted in Oceania regions [38-42], seven from North America [11, 43-48], three from South America, two from Europe [49-51], and 30 from Asia [17, 52-81] (Fig. 1). As a result, 16 studies met the eligibility criteria and were included in the systematic review and meta-analysis.

\section{Characteristics of original studies}

As described in Table 1, the 16 studies were published between 1999 to 2017. In the current meta-analysis, 13,286 study participants were included to estimate the pooled prevalence of DM among TB patients. Regarding study design, more than half $(56.3 \%)$ of the studies are cross-sectional. The sample size of the studies ranged from 107 to 4000 . The lowest prevalence (1.9\%) of DM was reported in a study conducted in Benin [30], whereas the highest prevalence (38\%) was reported in a study conducted in Nigeria [22]. In this meta-analysis, nine SSA countries were represented. Three of the studies were from Ethiopia [16, 26, 28]; four from Nigeria [19-22], two from Tanzania $[9,23]$, one each from Guinea-Bissau [25], 
Articles identified through electronic database search $(1,467)$ PubMed

(770), Google Scholar (89), Science Direct (428) and others (180)

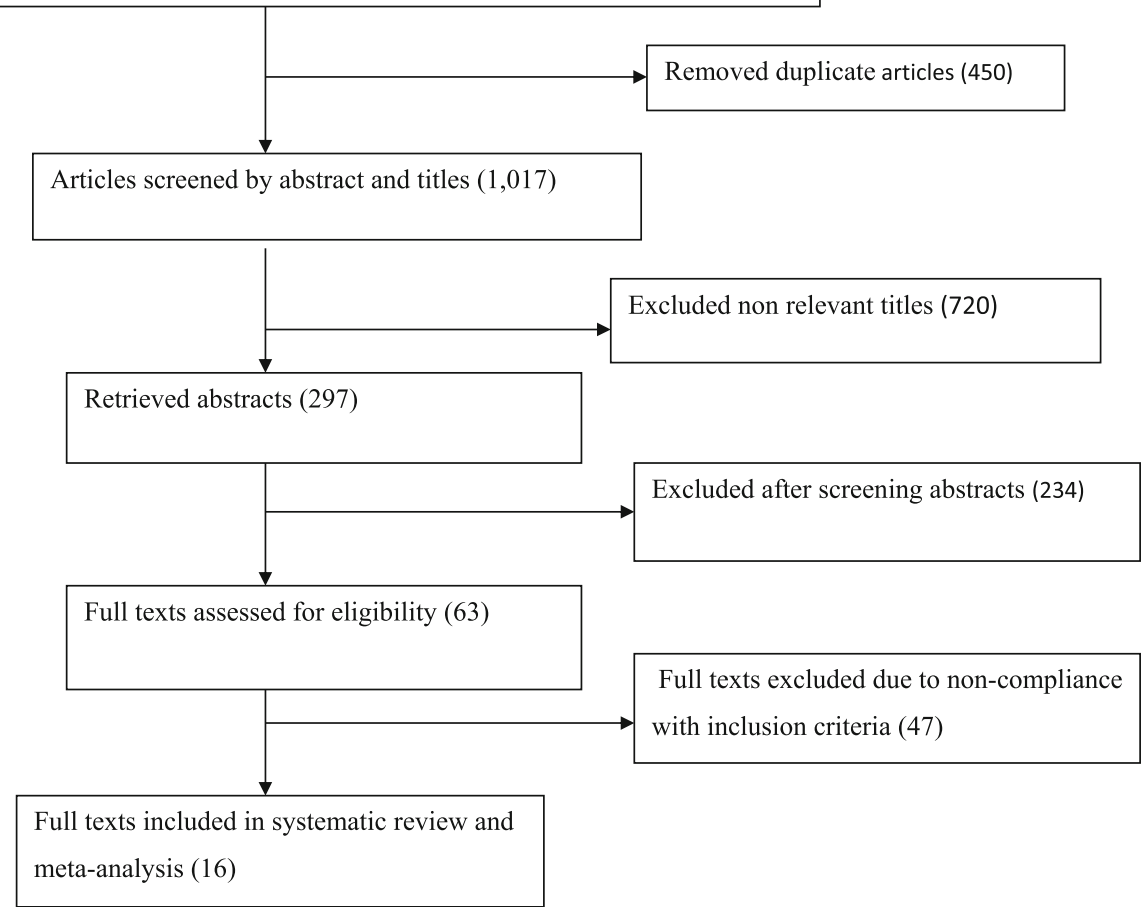

Fig. 1 Flow chart of study selection for systematic review and meta-analysis of the prevalence of DM among TB patients in SSA

Table 1 Descriptive summary of 16 studies included in the meta-analysis of the prevalence of diabetes mellitus among Tuberculosis patients in Sub-Saharan Countries, 2017

\begin{tabular}{|c|c|c|c|c|c|c|}
\hline Study period & Publication year & Country & Study design & Study period & Sample size & $\begin{array}{l}\text { Prevalence with } \\
95 \% \mathrm{Cl}\end{array}$ \\
\hline Ade et al. [30] & 2015 & Cotonou-Benin & Cross-sectional & June-July/ 2014 & 159 & $1.9(1,5)$ \\
\hline Faurholt-Jepsen et al. [9] & 2011 & Tanzania & Case control & Apr 2006-Jan 2009 & 803 & $16(14,19)$ \\
\hline Haraldsdottir et al. [25] & 2015 & Guinea-Bissau & NR & July 2010-July 2011 & 107 & $2.8(1,8)$ \\
\hline Kibirige et al. [24] & 2013 & Uganda & Cross-sectional & Sep 2011-Feb 2012 & 260 & $8.5(6,12)$ \\
\hline Ogbera et al. [21] & 2014 & Nigeria & Cross-sectional & Sep 2010-Mar 2012 & 3,376 & $4.8(4,8)$ \\
\hline Olayinka et al. [19] & 2013 & Nigeria & Cross-sectional & NR & 351 & $5.7(4,9)$ \\
\hline Workneh et al. [16] & 2016 & Ethiopia & Cross-sectional & Sep 2103-Sep 2014 & 1,314 & $8.3(7,10)$ \\
\hline Ogbera et al. [20] & 2015 & Nigeria & Descriptive observational study & Mar 2011-July 2012 & 4,000 & $12(11,13)$ \\
\hline Getachew et al. [26] & 2014 & Ethiopia & Cross-sectional & Oct 2011-Aug 2012 & 199 & $8.5(5,13)$ \\
\hline Damtew et al. [28] & 2014 & Ethiopia & Cross-sectional & Feb2014-May 2014 & 120 & $16(10,23)$ \\
\hline Balad et al. [29] & 2006 & Guinea & NR & Feb -June 2002 & 388 & $3.4(2,6)$ \\
\hline Rakotonirina et al. [17] & 2014 & Madagascar & Descriptive & July15-Oct.30,2013 & 156 & $5.8(3,11)$ \\
\hline Mugusi et al. [23] & 1999 & Tanzania & NR & NR & 506 & $6.7(5,9)$ \\
\hline Owiti et al. [18] & 2017 & Kenya & Cross-sectional & Jan -June 2016 & 454 & $6.7(3,7)$ \\
\hline Fonkeng et al. [27] & 2017 & Cameroon & Cross-sectional & Nov 2014-July 2015 & 222 & $9.5(6,19)$ \\
\hline Ekeke et al. [22] & 2017 & Nigeria & Prospective study & NR & 871 & $38(35,41)$ \\
\hline
\end{tabular}


Cotonou-Benin [30], Uganda [24], Guinea [29], Madagascar [17], Kenya [18], and Cameroon [27].

\section{Quality assessment}

The quality score of each original study ranged from four to eight (see Additional file 1). Regarding the sampling techniques used, majority ( $n=15,93.8 \%)$ of the included studies used consecutive sampling technique to select study participants $[9,16,17,20,21,23-25,27-30,82]$. Concerning the laboratory methods used to diagnose DM, seven studies used FBG [17, 19, 21, 28-30], four used RBS $[16,24,25,27]$, one each used OGT [23], HbA1c [18], and FBG and OGT [9], two studies did not report the methods used [20, 82]. Regarding study settings, seven out of sixteen studies conducted in hospitals [19, 23, 24, 26-29] and five in health centers $[16,18,20,30,82]$.

\section{Meta-analysis}

As presented in Fig. 2, this meta-analysis found that that the pooled proportion of DM among TB patients in SSA was found to $9 \%$ (95\% CI: 6, 12). The included studies exhibited high heterogeneity $\left(I^{2}=97.5 \%\right.$ with Cochrane Q-statistics $p$-value $<0.001)$ because of this, the final overall prevalence was computed based on a random effects meta-analysis model. Additionally, we conducted an advanced statistical meta-analysis model such as a univariate meta-regression model by considering publication year and sample size as covariates to identify the possible sources of random variations across primary studies. Nevertheless, these variables were not statistically significant source of heterogeneity (Table 2). Finally, the possibility of publication biases across primary studies were examined using Begg's correlation and Egger's regression tests. The test results, showed that there was no statistically significant publication bias across the included studies $(p$-values $=0.15$ and $=0.3$ respectively).

\section{Subgroup analysis}

In this meta-analysis, we performed a subgroup analysis based on the country where the studies were conducted and sample size of the studies. Accordingly, the highest prevalence was observed in Nigeria with a prevalence of 15\% (95\% CI: 7, 23), followed by Tanzania 11\% (95\% CI: 9, 12), and then Ethiopia at 10\% (95\% CI: 6, 13) (Table 3). With regard to sample size, the prevalence of diabetes was higher in studies having a sample size $\geq 300$ patients, $11 \%$ (95\% CI: 7, 15) compared to those having a sample size $<300$ patients, $7 \%$ (95\% CI: 4,10$)$. We compared the prevalence of DM among HIV infected and uninfected TB patients by including the reports of eight studies [16, 18, 22, 24, 26-28, 82]. The results of these studies indicated that the prevalence of DM among HIV infected TB patients was $8.9 \%$ (95CI 6.5, 11.3) which is higher than uninfected $\mathrm{TB}$ patients estimated at $7.7 \%$

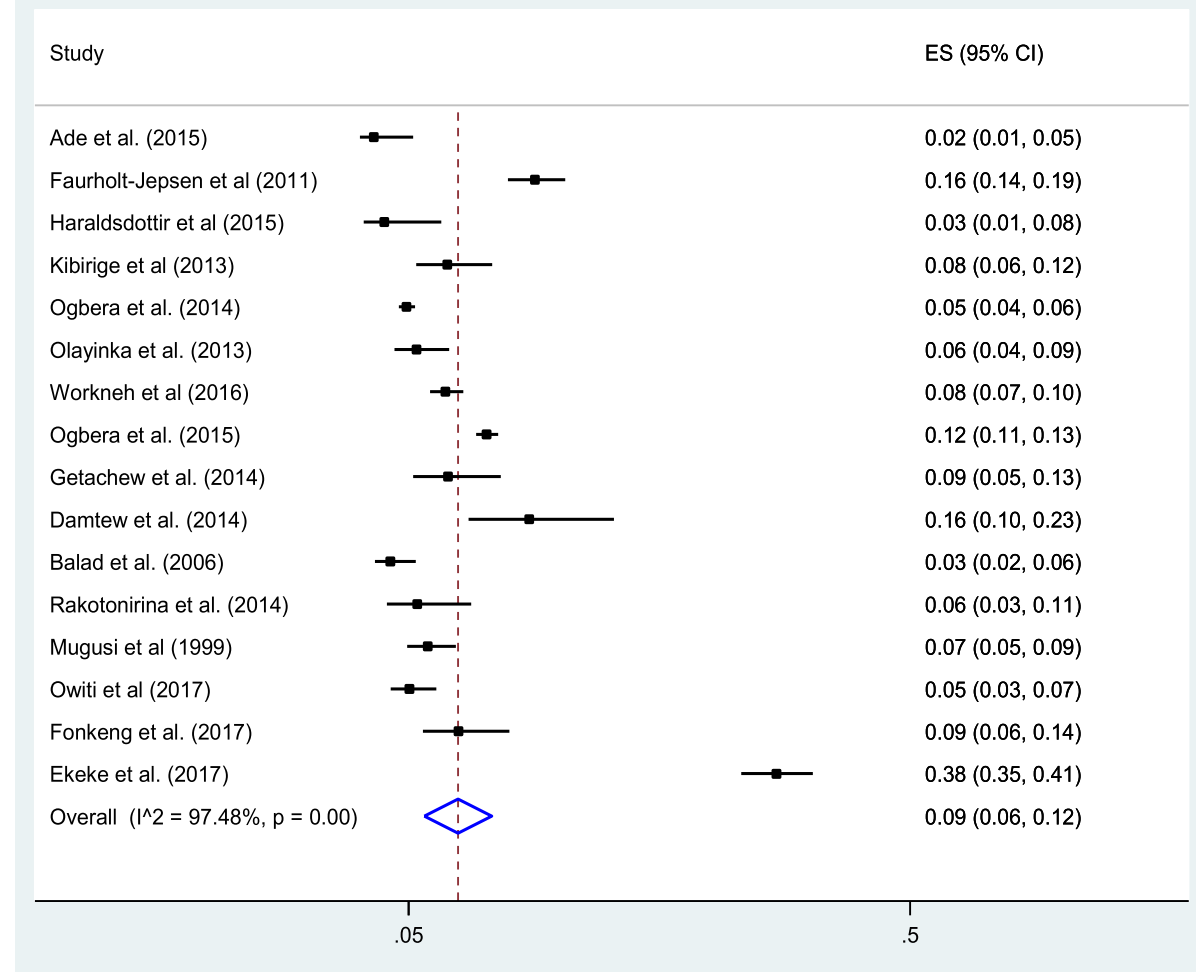

Fig. 2 Forest plot of the pooled prevalence of DM among TB patients in SSA 
Table 2 Related factors with heterogeneity of diabetes mellitus prevalence among tuberculosis patients in the current metaanalysis (based on univariate meta-regression)

\begin{tabular}{lll}
\hline Variables & Coefficient & P-value \\
\hline Publication year & -0.083 & 0.79 \\
Sample size & 0.001 & 0.47 \\
\hline
\end{tabular}

(95\%CI: 5.4, 10.1). High heterogeneity $\left(\mathrm{I}^{2}=78.3 \%\right.$ and $P$-value $<0.001)$ was observed across the included studies; hence, a random effects meta-analysis model was employed to compare the prevalence of DM between HIV infected and uninfected TB patients. Furthermore, we conducted a subgroup analysis based on the geographic residence (urban versus rural) of patients. However, in this study, there was no difference in the prevalence of DM among TB patients between urban (9\%) and rural (9\%) (Table 3).

\section{Discussion}

To the best our knowledge, this meta-analysis is the first of its kind to estimate the pooled prevalence of DM among TB patients in SSA region. However, the increased prevalence of DM-TB co-morbidity is rapidly becoming a major public health problem throughout the world, including resource-limiting settings, especially in high TB burden countries. Determining the pooled prevalence of DM among TB patients potentially catalyzes program and policy-makers to take remedial action.

The findings of this study showed that the pooled prevalence of DM among TB patients was 9\% (95\% CI: $6,12)$. The prevalence obtained from this meta-analysis is in line with the estimated prevalence of DM (8.516.4\%) among TB patients in SSA [19, 29, 83-85], and South America 11.1\% (IQR: 6.1-14\%) [86] as reported in a previous systematic review conducted on DM and TB co-morbidity. However, this finding is higher than the estimated prevalence of DM (2.1-6.7\%) among the general SSA population [87]. This finding is also slightly higher than the estimated prevalence of DM (5.9\%) among TB patients in European countries [86]. On the other hand, our finding is much lower than the estimated prevalence of DM among TB patients in Asian countries 17\% (IQR 11.4-25.8\%), North America 23.6\% (IQR: 17.3$35.4 \%$ ), and Oceania $23.3 \%$ (IQR: $12.8-39.0 \%$ ) as reported in a previous systematic review conducted on DM and TB co-morbidity [86]. A possible source of regional variation in the prevalence of DM among TB patients might be attributable to the differences in the general population prevalence of DM in the respective countries. The above discrepancies align with the estimated prevalence of DM among the adult population [88]. According to the WHO (2016), the prevalence of DM by region were 7.1\% (SSA), 8.3\% (America), 13.7\% (Mediterranean), 7.3\% (Europe), 8.6\% (South-East Asia), and 8.4\% (Western Pacific) [88].

In this meta-analysis, the lowest prevalence $(1.9 \%)$ of DM was observed in a study conducted in Benin [30], whereas the highest prevalence (38\%) was observed in a study conducted in Nigeria [22]. This high disparity in the prevalence of above studies could be due to the various techniques used to diagnose DM among TB patients and possibly the effects of co-morbidities such as HIV. From the included 16 studies, seven studies used FBG technique to diagnose DM [17, 19, 21, 28-30]. Concerning the diagnosis methods of DM among TB patients, no standard diagnostic method has been advocated for TB patients; hence, either a RBS, FBG, OGTT or HbA1c test can be used alone or in combination [7].

The subgroup analysis of this study showed that the pooled prevalence of DM among TB patients in Nigeria was $15 \%$ (95\% CI: 7,23$)$ which is higher than the prevalence in Tanzania 11\% (95\% CI: 9, 12), Ethiopia 10\% (95\% CI; 6, 13), and others 5\% (95\% CI: 3, 7). The possible explanations for this variation might be due to socioeconomic and sociocultural differences between the populations. Another possible explanation for this variation might

Table 3 Subgroup prevalence of diabetes mellitus among tuberculosis patients in Sub-Saharan African countries, 2017 ( $n=16$ )

\begin{tabular}{|c|c|c|c|c|}
\hline Variables & Characteristics & Number of studies included & Sample size & Estimate $(95 \% \mathrm{Cl})$ \\
\hline \multirow[t]{4}{*}{ Country } & Nigeria & 4 & 4998 & $15(7,23)$ \\
\hline & Ethiopia & 3 & 1633 & $10(6,13)$ \\
\hline & Tanzania & 2 & 1309 & $11(9,12)$ \\
\hline & Others & 7 & 5345 & $5(3,7)$ \\
\hline \multirow[t]{2}{*}{ Sample size } & $\geq 300$ & 9 & 12,063 & $11(7,15)$ \\
\hline & $<300$ & 7 & 1,223 & $7(4,10)$ \\
\hline \multirow[t]{2}{*}{ HIV infection } & HIV Positive & 9 & 1365 & $8.9(6.5,11.3)$ \\
\hline & HIV negative & 9 & 6,584 & $7.7(5.4,10.1)$ \\
\hline \multirow[t]{2}{*}{ Residence } & Urban & 5 & 2,269 & $9(8,11)$ \\
\hline & Rural & 5 & 1700 & $9(5,12)$ \\
\hline Overall & & 16 & 13,286 & $9(6,12)$ \\
\hline
\end{tabular}


be differences in the screening methods used, and variations in the prevalence of DM in the general population of the respective countries. Regional variation with regard to the burden of TB might have an impact on the prevalence of DM. According to WHO (2016), the incidence of TB in Nigeria was 322 per 100,000 while lower incidence of TB was noted in other countries like Ethiopia and Tanzania [89]. Similarly, from this subgroup analysis, we observed that the estimated prevalence of DM among TB patients in Nigeria was $15 \%$, which is much higher than the estimated prevalence of DM among the general population. Likewise, from the above subgroup analysis, we found that the pooled prevalence of DM among TB patients in Ethiopia was 10\%, which is almost twice the prevalence of DM among the general population. Moreover, the estimated prevalence of DM among TB patients in Tanzania was $11 \%$, which is also higher than the estimated prevalence of DM among the general population.

In this study, we tried to compare the prevalence of DM between HIV infected and uninfected TB patients. This result reflects that the overall prevalence of DM among HIV infected TB patients is (8.9\%) which is lightly higher than uninfected TB patients (7.7\%). This finding is comparable with previous findings showing that people living with HIV have a higher risk of developing DM due to side effects of certain HIV medicines which may increase blood glucose levels and lead to Type 2 DM [90]. Studies have suggested that prolonged exposure of the anti-retroviral medication can be an aggravating factor for the occurrence of DM. In addition, another study also indicated that HIV infection was significantly associated with higher incidence of DM, with a reported incidence of DM per 100 person-years among HIV infected group as 2.44, which is significantly higher than the incidence reported in their HIV negative counterparts (1.89 per 100 person-years) [91].

\section{Limitations of the study}

Despite the authors performed a comprehensive search using different databases to address all articles conducted on the prevalence of DM among TB patients in SSA, this systematic review failed to include papers published other than the English language. To boot, this systematic review included only 16 studies involving 13,286 TB patients. Therefore, this systematic review relatively analyzed data of limited number of study participants and this factor could significantly affects the estimated reports. Furthermore, during our search, we found studies only from the nine countries of SSA region and other countries may be under-represented due to the limited number of studies included. At last, the results obtained from this review should be interpreted cautiously because more than half (56.3\%) of the studies included in the meat-analysis had cross-sectional study design. It is well known that the reports of cross-sectional type of study designs are highly influenced by confounding variables.

\section{Conclusion}

In conclusion, the pooled prevalence of DM among $\mathrm{TB}$ patients in SSA was significantly high. This review found that the prevalence of DM among HIV-infected TB patients is higher than HIV-uninfected TB patients. Because of the frequent co-morbidity of these two diseases, focusing on signs of diabetes among patients with TB, particularly if the risk factors are present, could contribute to improved detection and early treatment of diabetes in this population. Therefore, based on our findings, we recommend consideration of the potential for routine screening for DM among TB patients. Moreover, a special emphasis should be given for early screening of DM among TB/HIV co-infected patients.

\section{Additional file}

Additional file 1: Quality score of each study. (DOCX $27 \mathrm{~kb}$ )

\section{Abbreviations}

Cl: Confidence Interval; DM: Diabetes Mellitus; FBG: Fast Blood Glucose; HIV: Human Immunodeficiency Virus; NCD: Non-communicable Disease; NOS: Newcastle Ottawa Scale; PTB: Pulmonary Tuberculosis; RBG: Random Blood Glucose; SSA: Sub-Saharan Africa; TB: Tuberculosis

\section{Acknowledgments}

Not applicable

Funding

No funding was obtained for this study.

Availability of data and materials

Data will be available upon request of the corresponding author.

\section{Authors' contributions}

AA1: Conception of research protocol, study design, literature review, data extraction, data analysis, interpretation and drafting the manuscript. ATW, CT, GDK, FW, PP, AA2, ADA, MA, and SE: data analysis, reviewing the manuscript, data extraction and quality assessment. All authors have read and approved the manuscript.

Ethics approval and consent to participate

Not applicable

Consent for publication

Not applicable

\section{Competing interests}

The authors declare that they have no competing interests.

\section{Publisher's Note}

Springer Nature remains neutral with regard to jurisdictional claims in published maps and institutional affiliations.

\section{Author details}

${ }^{1}$ College of Health Sciences, Debre Markos University, P.O. Box 269, Debre Markos, Ethiopia. ${ }^{2}$ College of Nursing, University of Saskatchewan, Saskatoon, Canada. ${ }^{3}$ School of Life Sciences and Bioengineering, Nelson Mandela African Institute of Science and Technology, Arusha, Tanzania. ${ }^{4}$ School of Science and Health, Western Sydney University, Penrith, NSW 2751, Australia. 
${ }^{5}$ Translational Health Research Institute, Western Sydney University, Penrith, NSW 2751, Australia. 'Discipline of Child and Adolescent Health, Sydney Medical School, Faculty of Medicine and Health, The University of Sydney, Westmead, NSW 2145, Australia. ${ }^{7}$ Oral Health Services, Sydney Local Health District and Sydney Dental Hospital, NSW Health, Surry Hills, NSW 2010, Australia. ${ }^{8}$ College of Medicine and Health Sciences, University of Gondar, Gondar, Ethiopia.

\section{Received: 3 April 2018 Accepted: 7 March 2019}

Published online: 13 March 2019

\section{References}

1. Mathers CD, Loncar D. Projections of global mortality and burden of disease from 2002 to 2030. PLoS Med. 2006;3(11):e442.

2. Wild SH, Roglic G, Green A, Sicree R, King H. Global prevalence of diabetes: estimates for the year 2000 and projections for 2030: response to Rathman and Giani. Diabetes Care. 2004;27(10):2569.

3. King H, Aubert RE, Herman WH. Global burden of diabetes, 1995-2025: prevalence, numerical estimates, and projections. Diabetes Care. 1998;21(9): 1414-31.

4. Aguiree F, Brown A, Cho N, Dahlquist G, Dodd S, Dunning T, Hirst M, Hwang C, Magliano D, Patterson C. International diabetes federation diabetes atlas. Brussels: International Diabetes Federation; 2013.

5. International Diabetes Federation Diabetes Atlas. http://www.idf.org/ diabetesatlas/5e/ Accessed Clon 26/06/2012.

6. Hall V, Thomsen RW, Henriksen O, Lohse N. Diabetes in sub Saharan Africa 1999-2011: epidemiology and public health implications. A systematic review. BMC Public Health. 2011;11:564.

7. Ottmani S, Murray M, Jeon C, Baker M, Kapur A, Lönnroth K, Harries A. Consultation meeting on tuberculosis and diabetes mellitus: meeting summary and recommendations [meeting report]. Int J Tuberc Lung Dis. 2010;14(12):1513-7.

8. Jeon CY, Murray MB. Diabetes mellitus increases the risk of active tuberculosis: a systematic review of 13 observational studies. PLoS Med. 2008;5(7):e152.

9. Faurholt-Jepsen D, Range N, PrayGod G, Jeremiah K, Faurholt-Jepsen M, Aabye MG, Changalucha J, Christensen DL, Pipper CB, Krarup H. Diabetes is a risk factor for pulmonary tuberculosis: a case-control study from Mwanza, Tanzania. PloS one. 2011;6(8):e24215.

10. Sen T, Joshi SR, Udwadia ZF. Tuberculosis and diabetes mellitus: merging epidemics. J Assoc Physicians India. 2009:57(1):399-404.

11. Magee MJ, Kempker RR, Kipiani M, Gandhi NR, Darchia L, Tukvadze N, Howards PP, Narayan KV, Blumberg HM. Diabetes mellitus is associated with cavities, smear grade, and multidrug-resistant tuberculosis in Georgia. Int J Tuberc Lung Dis. 2015;19(6):685-92.

12. Baker MA, Harries $A D$, Jeon $C Y$, Hart JE, Kapur A, Lönnroth $K$, Ottmani S-E, Goonesekera SD, Murray MB. The impact of diabetes on tuberculosis treatment outcomes: a systematic review. BMC Med. 2011:9(1):81.

13. Mboussa J, Monabeka H, Kombo M, Yokolo D, Yoka-Mbio A, Yala F. Course of pulmonary tuberculosis in diabetics. Rev Pneumol Clin. 2003:59(1):39-44.

14. Koziel H. Pulmonary complication of diabetes mellitus: pneumonia. Infect Dis Clin N Am. 1995:9:1-9.

15. Van Cromphaut S, Vanhorebeek I, Van den Berghe G. Glucose metabolism and insulin resistance in sepsis. Curr Pharm Des. 2008;14(19):1887-99.

16. Workneh MH, Bjune GA, Yimer SA. Prevalence and associated factors of diabetes mellitus among tuberculosis patients in south-eastern Amhara region, Ethiopia: a cross sectional study. PLoS One. 2016;11(1):e0147621.

17. Rakotonirina J, Razanakoto H, Rasolofomanana L, Razanakolona LR-S. HIV prevalence and diabetes prevalence among tuberculosis patients in Antananarivo city: a descriptive study; 2014.

18. Owiti P, Keter A, Harries A, Pastakia S, Wambugu C, Kirui N, Kasera G, Momanyi R, Masini E, Some F. Diabetes and pre-diabetes in tuberculosis patients in western Kenya using point-of-care glycated haemoglobin. Public Health Action. 2017;7(2):147-54

19. Olayinka AO, Anthonia O, Yetunde K. Prevalence of diabetes mellitus in persons with tuberculosis in a tertiary health Centre in Lagos, Nigeria. Indian J Endocrinol Metab. 2013;17(3):486.

20. Ogbera AO, Kapur A, Abdur-Razzaq H, Harries AD, Ramaiya K, Adeleye O Kuku S. Clinical profile of diabetes mellitus in tuberculosis. BMJ Open Diabetes Res Care. 2015;3(1):e000112.
21. Ogbera A, Kapur A, Odeyemi K, Longe-Peters K, Adeyeye OO, Odeniyi I, Ogunnowo B. Screening for diabetes mellitus and human immunodefiency virus infection in persons with tuberculosis. J Prev Med Hyg. 2014;55(2):42.

22. Obiora NN, Azuonye OR, Oluoha NV, Uche OC. Prevalence of diabetes mellitus among pulmonary tuberculosis suspects in Nnewi, Nigeria. J Microbiol Biotechnol Res. 2017;6(2):1-5.

23. Mugusi F, Swai A, Alberti K, McLarty D. Increased prevalence of diabetes mellitus in patients with pulmonary tuberculosis in Tanzania. Tubercle. 1990;71(4):271-6.

24. Kibirige D, Ssekitoleko R, Mutebi E, Worodria W. Overt diabetes mellitus among newly diagnosed Ugandan tuberculosis patients: a cross sectional study. BMC Infect Dis. 2013;13(1):122.

25. Haraldsdottir TL, Rudolf F, Bjerregaard-Andersen M, Carlos Joaquím L Stochholm K, Gomes VF, Beck-Nielsen H, Ostergaard L, Aaby P, Wejse C. Diabetes mellitus prevalence in tuberculosis patients and the background population in Guinea-Bissau: a disease burden study from the capital Bissau. Trans R Soc Trop Med Hyg. 2015;109(6):400-7.

26. Getachew A, Mekonnen S, Alemu S. High magnitude of diabetes mellitus among active pulmonary tuberculosis patients in Ethiopia; 2014.

27. Fonkeng LS, Ali IM, Noubom M, Bamou R, Sterve AH, Leo A, Kuiate J, Tume CB. Prevalence, Predictors and Treatment Outcome of Type 2 Diabetes among Newly Diagnosed Sputum Positive Pulmonary Tuberculosis Patients in Western Cameroon. J Infect Dis Epidemiol. 2017;3:2.

28. Damtew E, Ali I, Meressa D. Prevalence of diabetes mellitus among active pulmonary tuberculosis patients at St. Peter specialized hospital, Addis Ababa, Ethiopia. World J Med Sci. 2014;11:389-96.

29. Balde N, Camara A, Camara L, Diallo M, Kake A, Bah-Sow O. Associated tuberculosis and diabetes in Conakry, Guinea: prevalence and clinical characteristics. Int J Tuberc Lung Dis. 2006;10(9):1036-40.

30. Ade S, Affolabi D, Agodokpessi G, Wachinou P, Faïhun F, Toundoh N, Békou W, Makpenon A, Ade G, Anagonou S. Low prevalence of diabetes mellitus in patients with tuberculosis in Cotonou, Benin. Public Health Action. 2015;5(2):147-9.

31. Liberati A, Altman DG, Tetzlaff J, Mulrow C, Gotzsche PC, loannidis JP, Clarke M Devereaux PJ, Kleijnen J, Moher D. The PRISMA statement for reporting systematic reviews and meta-analyses of studies that evaluate health care interventions: explanation and elaboration. J Clin Epidemiol. 2009;62(10):e1-34.

32. World Health Organization: Definition and diagnosis of diabetes mellitus and intermediate hyperglycaemia: report of a WHO/IDF consultation Available at https://scholar.google.com/scholar?hl=en\&as_sdt=0\%2C5\&q= World+Health+Organization.+Definition+and+diagnosis+of+diabetes +mellitus+and+intermediate+hyperglycemia.+2006.+Available\&btnG =. 2006

33. Ryu YJ. Diagnosis of pulmonary tuberculosis: recent advances and diagnostic algorithms. Tuberc Respir Dis. 2015;78(2):64-71.

34. Newcastle-Ottawa Scale customized for cross-sectional studies. In. available from https://static-content.springer.com/esm/.../12889_2012_5111_ MOESM3 ESM.doc.

35. Rücker G, Schwarzer G, Carpenter JR, Schumacher M. Undue reliance on I 2 in assessing heterogeneity may mislead. BMC Med Res Methodol. 2008;8:79.

36. Higgins JP, Altman DG. Assessing risk of bias in included studies, Cochrane handbook for systematic reviews of interventions: Cochrane book series: 2008. p. 187-241.

37. Borenstein M, Hedges LV, Higgins J, Rothstein HR. A basic introduction to fixed-effect and random-effects models for meta-analysis. Res Synth Methods. 2010;1(2):97-111.

38. Viney K, Cavanaugh J, Kienene T, Harley D, Kelly P, Sleigh A, O'connor J, Mase S. Tuberculosis and diabetes mellitus in the Republic of Kiribati: a case-control study. Tropical Med Int Health. 2015;20(5):650-7.

39. Prasad P, Gounder S, Varman S, Viney K. Sputum smear conversion and treatment outcomes for tuberculosis patients with and without diabetes in Fiji. Public health action. 2014;4(3):159-63.

40. Nasa J, Brostrom R, Ram S, Kumar A, Seremai J, Hauma M, Paul I, Langidrik J. Screening adult tuberculosis patients for diabetes mellitus in Ebeye, Republic of the Marshall Islands. Public Health Action. 2014:4(1):S50-2.

41. Gounder S, Harries A. Screening tuberculosis patients for diabetes mellitus in Fiji: notes from the field. Public Health Action. 2012;2(4):145-7.

42. Bridson T, Matthiesson A, Owens L, Govan B, Norton R, Ketheesan N. Diabetes: a contributor to tuberculosis in tropical Australia. Am J Trop Med Hyg. 2015;93(3):547-8

43. Suwanpimolkul G, Grinsdale JA, Jarlsberg LG, Higashi J, Osmond DH, Hopewell PC, Kato-Maeda M. Association between diabetes mellitus and 
tuberculosis in United States-born and foreign-born populations in San Francisco. PLoS One. 2014;9(12):e114442.

44. Restrepo BI, Camerlin AJ, Rahbar MH, Wang W, Restrepo MA, Zarate I, MoraGuzmán F, Crespo-Solis JG, Briggs J, McCormick JB. Cross-sectional assessment reveals high diabetes prevalence among newly-diagnosed tuberculosis cases. Bull World Health Organ. 2011;89(5):352-9.

45. Restrepo B, Fisher-Hoch S, Crespo J, Whitney E, Perez A, Smith B, McCormick J. Type 2 diabetes and tuberculosis in a dynamic bi-national border population. Epidemiol Infect. 2007;135(3):483-91.

46. Ponce-de-Leon A, de Lourdes G-GM, Garcia-Sancho MC, Gomez-Perez FJ, Valdespino-Gomez JL, Olaiz-Fernandez G, Rojas R, Ferreyra-Reyes L, CanoArellano B, Bobadilla M. Tuberculosis and diabetes in southern Mexico. Diabetes Care. 2004;27(7):1584-90.

47. Jiménez-Corona ME, Cruz-Hervert LP, García-García L, Ferreyra-Reyes L, Delgado-Sánchez G, Bobadilla-del-Valle M, Canizales-Quintero S, FerreiraGuerrero E, Báez-Saldaña R, Téllez-Vázquez N. Association of diabetes and tuberculosis: impact on treatment and post-treatment outcomes. Thorax. 2012;2012:201756.

48. Delgado-Sánchez G, García-García L, Castellanos-Joya M, Cruz-Hervert P, Ferreyra-Reyes L, Ferreira-Guerrero E, Hernández A, Ortega-Baeza VM, Montero-Campos R, Sulca JA. Association of pulmonary tuberculosis and diabetes in Mexico: analysis of the national tuberculosis registry 2000-2012. PLoS One. 2015;10(6):e0129312.

49. Reis-Santos B, Locatelli R, Horta BL, Faerstein E, Sanchez MN, Riley LW, Maciel EL. Socio-demographic and clinical differences in subjects with tuberculosis with and without diabetes mellitus in Brazil-a multivariate analysis. PLoS One. 2013;8(4):e62604.

50. Magee M, Bloss E, Shin S, Contreras C, Huaman HA, Ticona JC, Bayona J, Bonilla C, Yagui M, Jave O. Clinical characteristics, drug resistance, and treatment outcomes among tuberculosis patients with diabetes in Peru. Int J Infect Dis. 2013;17(6):e404-12.

51. Alladin B, Mack S, Singh A, Singh C, Smith B, Cummings E, Hershfield E, Mohanlall J, Ramotar K, La Fleur C. Tuberculosis and diabetes in Guyana. Int J Infect Dis. 2011;15(12):e818-21.

52. Viswanathan V, Kumpatla S, Aravindalochanan V, Rajan R, Chinnasamy C, Srinivasan R, Selvam JM, Kapur A. Prevalence of diabetes and pre-diabetes and associated risk factors among tuberculosis patients in India. PLoS One. 2012;7(7):e41367.

53. Siddiqui AM. Clinical manifestations and outcome of tuberculosis in diabetic patients admitted to King Abdulaziz University hospital in Jeddah, Saudi Arabia. J Taibah Univ Med Sci. 2009;4(2):148-55.

54. Shidam U, Roy G, Sahu S, Kumar S, Ananthanarayanan P. Screening for diabetes among presumptive tuberculosis patients at a tertiary care Centre in Pondicherry, India. Int J Tuberc Lung Dis. 2015;19(10):1163-8.

55. Shaikh MA, Singla R, Khan NB, Sharif NS, Saigh MO. Does diabetes alter the radiological presentation of pulmonary tuberculosis. Saudi Med J. 2003; 24(3):278-81.

56. Rajapakshe W, Isaakidis P, Sagili K, Kumar A, Samaraweera S, Pallewatta N, Jayakody W, Nissanka A. Screening patients with tuberculosis for diabetes mellitus in Ampara, Sri Lanka. Public Health Action. 2015;5(2):150-2.

57. Raghuraman S, Vasudevan KP, Govindarajan S, Chinnakali P, Panigrahi KC. Prevalence of diabetes mellitus among tuberculosis patients in urban Puducherry. N Am J Med Sci. 2014;6(1):30.

58. Prakash B, Ravish K, Prabhakar B, Ranganath T, Naik B, Satyanarayana S, Isaakidis $\mathrm{P}$, Kumar A. Tuberculosis-diabetes mellitus bidirectional screening at a tertiary care Centre, South India. Public Health Action. 2013;3(1):18-22.

59. Park S, Shin J, Kim J, Park I, Choi B, Choi J, Kim Y. The effect of diabetic control status on the clinical features of pulmonary tuberculosis. Eur J Clin Microbiol Infect Dis. 2012;31(7):1305-10.

60. Pablo-Villamor MP, Benedicto JP, Benedicto M, Perez VM. Screening for diabetes mellitus in patients diagnosed with pulmonary tuberculosis. Philipp J Intern Med. 2014;52(4):1-9.

61. Nair S, Kumari A, Subramonianpillai J, Shabna D, Kumar S, Balakrishnan S, Naik B, Kumar A, Isaakidis P, Satyanarayana S. High prevalence of undiagnosed diabetes among tuberculosis patients in peripheral health facilities in Kerala. Public Health Action. 2013;3(1):38-42.

62. Nagar V, Gour D, Arutagi V, Dave L, Bhatia P, Joshi A, Pal D. A study to assess the blood glucose level among diagnosed cases of tuberculosis registered at a tuberculosis unit of Bhopal city, Madhya Pradesh, India. Int J Med Sci Public Health. 2015;4(2):245-9.
63. Mi F, Jiang G, Du J, Li L, Yue W, Harries AD, Hinderaker SG, Lin Y. Is resistance to anti-tuberculosis drugs associated with type 2 diabetes mellitus? A register review in Beijing, China. Glob Health Action. 2014;7(1):24022.

64. Mehta S, Yu EA, Ahamed SF, Bonam W, Kenneth J. Rifampin resistance and diabetes mellitus in a cross-sectional study of adult patients in rural South India. BMC Infect Dis. 2015;15(1):451.

65. Lin Y-H, Chen C-P, Chen P-Y, Huang J-C, Ho C, Weng H-H, Tsai Y-H, Peng Y$\mathrm{S}$. Screening for pulmonary tuberculosis in type 2 diabetes elderly: a crosssectional study in a community hospital. BMC Public Health. 2015;15(1):3.

66. Li L, Lin Y, Mi F, Tan S, Liang B, Guo C, Shi L, Liu L, Gong F, Li Y. Screening of patients with tuberculosis for diabetes mellitus in China. Tropical Med Int Health. 2012;17(10):1294-301.

67. Kumpatla S, Sekar A, Achanta S, Sharath B, Kumar A, Harries A, Viswanathan $V$. Characteristics of patients with diabetes screened for tuberculosis in a tertiary care hospital in South India. Public Health Action. 2013;3(1):23-8.

68. Jawad F, Shem A, Memon R, Ansari G. Glucose intolerance in pulmonary tuberculosis. J Pakistan Med Assoc. 1995;45:237-8.

69. Jali MV, Mahishale VK, Hiremath MB. Bidirectional screening of tuberculosis patients for diabetes mellitus and diabetes patients for tuberculosis. Diabetes Metab J. 2013;37(4):291-5.

70. Jali MV, Mahishale VK, Hiremath M, Satyanarayana S, Kumar A, Nagaraja S, Isaakidis P. Diabetes mellitus and smoking among tuberculosis patients in a tertiary care Centre in Karnataka, India. Public health action. 2013;3(1):51-3.

71. Jabbar A, Hussain S, Khan A. Clinical characteristics of pulmonary tuberculosis in adult Pakistani patients with co-existing diabetes mellitus; 2006.

72. Duangrithi D, Thanachartwet V, Desakorn V, Jitruckthai P, Phojanamongkolkij K, Rienthong S, Chuchottaworn C, Pitisuttithum P. Impact of diabetes mellitus on clinical parameters and treatment outcomes of newly diagnosed pulmonary tuberculosis patients in Thailand. Int J Clin Pract. 2013;67(11):1199-209.

73. Dave P, Shah A, Chauhan M, Kumar A, Harries A, Malhotra S, Pujara K, Patel $P$, Mane M, Thakkar A. Screening patients with tuberculosis for diabetes mellitus in Gujarat, India. Public Health Action. 2013:3(1):29-33.

74. Chen H, Liu M, Jiang S, Gu F, Huang S, Gao T, Zhang Z. Impact of diabetes on diagnostic delay for pulmonary tuberculosis in Beijing. Int J Tuberc Lung Dis. 2014;18(3):267-71.

75. Chaudhry LA, Essa EB, Al-Solaiman S, Al-Sindi K. Prevalence of diabetes type-2 \& pulmonary tuberculosis among Filipino and treatment outcomes: a surveillance study in the eastern Saudi Arabia. Int J Mycobacteriol. 2012; 1(2):106-9.

76. Chachra V, Arora V. Study on prevalance of diabetes mellitus in patients with TB under DOTS strategy. Indian J Tuberc. 2014;61(1):65-71.

77. Balakrishnan S, Vijayan S, Nair S, Subramoniapillai J, Mrithyunjayan S, Wilson N, Satyanarayana S, Dewan PK, Kumar AM, Karthickeyan D. High diabetes prevalence among tuberculosis cases in Kerala, India. PloS one. 2012;7(10): e46502.

78. Baghaei P, Tabarsi P, Marjani M, Moniri A, Masjedi MR. Screening for diabetes mellitus in tuberculosis patients in a referral center in Iran. Infect Dis. 2015;47(7):472-6.

79. Amin S, Khattak MI, Shabbier G, Wazir MN. Frequency of pulmonary tuberculosis in patients with diabetes mellitus. Gomal J Med Sci. 2012;9:2.

80. Alisjahbana B, Van Crevel R, Sahiratmadja E, Den Heijer M, Maya A, Istriana E, Danusantoso H, Ottenhoff T, Nelwan R, Van Der Meer J. Diabetes mellitus is strongly associated with tuberculosis in Indonesia. Int J Tuberc Lung Dis. 2006;10(6):696-700.

81. Achanta S, Tekumalla R, Jaju J, Purad C, Chepuri R, Samyukta R, Malhotra S, Nagaraja S, Kumar A, Harries A. Screening tuberculosis patients for diabetes in a tribal area in South India. Public Health Action. 2013;3(1):43-7.

82. Ekeke N, Ukwaja KN, Chukwu JN, Nwafor CC, Meka AO, Egbagbe EE, Soyinka FO, Alobu I, Agujiobi I, Akingbesote S. Screening for diabetes mellitus. among tuberculosis patients in southern Nigeria: a multi-Centre implementation study under programme settings. Sci Rep. 2017;7:44205.

83. Marais R. Diabetes mellitus in black and coloured tuberculosis patients. S Afr Med J= Suid-Afrikaanse tydskrif vir geneeskunde. 1980;57(13):483-4.

84. Faurholt-Jepsen D, Range N, PrayGod G, Jeremiah K, Faurholt-Jepsen M, Aabye M, Changalucha J, Christensen DL, Witte DR, Andersen A. The role of anthropometric and other predictors for diabetes among urban Tanzanians with tuberculosis. Int J Tuberc Lung Dis. 2012;16(12):1680-5.

85. Atlas D: International Diabetes Federation, 2009. Online version of Diabetes Atlas: www eatlas idf org 2013. 
86. Workneh MH, Bjune GA, Yimer SA. Prevalence and associated factors of tuberculosis and diabetes mellitus comorbidity: a systematic review. PLoS One. 2017;12(4):e0175925.

87. Unwin N, Whiting D, Guariguata L. International Diabetes Federation. IDF diabetes atlas. Brussels: International Diabetes Federation; 2012. In.; 2013

88. World Health Organization: Global report on diabetes WHO Library Cataloguing-in-Publication Data Available from http://apps.who.int/iris/ bitstream/10665/204871/1/9789241565257_eng.pdf 2016.

89. World Health Organization: Global Tuberculosis Report Available at http://www.who.int/tb/publications/global_report/gtbr2016_executive_ summary.pdf?ua=1. 2016.

90. U.S. Department of Health and Human Services: HIV and Diabetes | Understanding HIV/AIDS | AIDSinfo available https://aidsinfo.nih.gov/ understanding-hiv-aids/fact-sheets/22/59/hiv-and-diabetes. 2016.

91. Tien PC, Schneider MF, Cox C, Karim R, Cohen M, Sharma A, Young M, Glesby MJ. Association of HIV infection with incident diabetes mellitus: impact of using hemoglobin A1C as a criterion for diabetes. J Acquir Immune Defic Syndr (1999). 2012;61(3):334-40.

Ready to submit your research? Choose BMC and benefit from:

- fast, convenient online submission

- thorough peer review by experienced researchers in your field

- rapid publication on acceptance

- support for research data, including large and complex data types

- gold Open Access which fosters wider collaboration and increased citations

- maximum visibility for your research: over $100 \mathrm{M}$ website views per year

At $\mathrm{BMC}$, research is always in progress.

Learn more biomedcentral.com/submissions 